\title{
EXPOSURE HAZARD ANALYSIS IN CEMENT FIBER SHEET MANUFACTURING INDUSTRY
}

\author{
M. Rajesh Kumar ${ }^{1}$, K. N. Karthick ${ }^{2}$, T. Dheenathayalan ${ }^{3}$, K. Visagavel $^{4}$ \\ ${ }^{1}$ PG Scholar, Industrial Safety Engineering, Knowledge Institute of Technology, Salem, India \\ ${ }^{2}$ Assistant Professor, Department of Mechanical Engineering, Knowledge Institute of Technology, Salem, India. \\ ${ }^{3}$ Assistant Professor, Department of Mechanical Engineering, Knowledge Institute of Technology, Salem, India \\ ${ }^{4}$ Professor, Department of Mechanical Engineering, Knowledge Institute of Technology, Salem, India
}

\begin{abstract}
Asbestos a collective name given to six type of naturally occurring fiber, well known human carcinogen. Undesirable health effects of asbestos lead to prohibition in most of developed countries but still some developing countries tend to use it in various commercial form. The objective of this study is to estimate the occupational asbestos exposure level and to predict the health risk if the level of exposure exceeds the recommended standard limit. One of the asbestos cement (AC) sheet manufacturing industry is selected to conduct study similar to general cross-sectional study. The main operation of the industry is to manufacture AC sheet in continuous basic that mean production is done round the clock. Both personal sample and static sample were collected in regular operational day by following BIS 11450:2006 as standard procedure for collecting air samples and fiber counting. Location for sampling were selected by considering staff suggestion and by visual observation made around the occupancy area. From twenty-four collected samples twenty-two were sampled, the personal sample taken from wet ball mill area shown 0.0690 fiber per cubic centimetre (f/cc) which was highest among overall collected sample and lowest concentration $0.0195 \mathrm{f} / \mathrm{cc}$ was found from personal testing fiber sheet. From the obtained fiber concentration result it shows that asbestos exposure at occupational area were maintained within the permissible limit also no history of asbestos related diseases (ARD) was found among employees which hypothesis the progressive safety system in working environment. Unless until the use of asbestos is completely prohibited, a finest control system should be followed to avoid the occurrence of ARD from both occupational and public zone.
\end{abstract}

Key Words: Asbestos, fiber concentration, occupational asbestos exposure and sampling.

\section{INTRODUCTION}

Asbestos is universally recognized as human carcinogenic that can result in chronic disease such as mesothelioma, lung cancer, chromosomal alteration and [1]-[5]. Asbestos are mainly categorised as two type's amphiboles (Actinolite, Amosite, Anthophyllite, Crocidolite, tremolite) and serpentine (Chrysotile) [2], [6], [7]. This fiber can be found as natural rock in certain parts of the world, among world countries Russia and Canada are the largest exporters[6] of asbestos fiber especially chrysotile, commercially termed as white fiber. Chrysotile can be found in many different commercial products that include cement products, automobile brake lining [6]. There were few studies which show non-significant [8], [9] health effect of chrysotile fiber but numerous show significant association with asbestos related diseases. Although all types of asbestos are health hazardous this white fiber is proved as less hazardous than its other types [10]. But in recent years chrysotile fiber has become a threat to human health. Various studies has been done in aspect of risk assessment, occupational exposure and mortality rate determination which are now used as tool to create awareness and this current study follows same way.
Each country has set of protocol to assess the occupational exposure level, in India Bureau of Indian standard (BIS) 11450 is used to assess the airborne asbestos fibre concentration in work environment by light microscopy [11]. Because of higher mortality rate and by evidence of ARD [12] from occupational and non-occupational asbestos exposure many countries had banned the use of asbestos. By economic consideration some countries still manufacture and uses asbestos based product [13], in those industry it is mandatory to assess the level of exposure and to maintain safe working condition.

This study will help to reveal the actual asbestos exposure level in an AC sheet manufacturing industry.

\section{METHOD AND MATERIALS}

\subsection{Manufacturing Process}

A cement fiber sheet manufacturing industry was selected to carry out this study. Here the AC sheet are produced by following well known Hatscheck process which is carried out in wet condition. The raw material for the process involves cement, fly ash, chrysotile asbestos fiber and water. Each raw material are separately mixed with water to form unique slurry then they are stored in separate silo on 
requirement those slurry is fed to series of rotating hallow cylindrical vat attached with endless felt and sheet making machine. When expected thickness is achieved the sheet is automatically cut off into moving conveyor then sheet are corrugated by the standard profile. The sheet along with template are sent to heating chamber for initial curing that takes from 8 to $22 \mathrm{hrs}$. After initial curing sheet are switched to MS pallet for final curing at maturing bay by water showering for 15 days and they are shifted to open space for another 10 days for final maturing.

\subsection{Study Area}

Although cement sheet manufacturing process mostly follows same principle the sampling area/process was selected based on staff suggestion factor. Both personal sampling and static sampling are done for one hour constantly, personal sampling is made for workers at edge runner mill area, personal on fiber testing, moulded goods filling area, salvaging area, forklift driver on carrying fiber bags. Static sampling is made at fiber storage area and fiber stack. Personal samples are collected at the breathing zone of personal. Fig 1 shows the picture taken at sample time.

\subsection{Fiber Monitoring Procedure}

BIS 11450:2006 is followed for air sampling, asbestos air monitoring was done with help of personal sampler APM 800 manufactured by Envirotech Instruments private Limited it is capable of sampling air at flow rate rages from 0.5 to 2 Liquid Per Minutes (LPM) here 1 LPM was maintained as content flow rate, ester cellulose filter of 25 $\mathrm{mm}$ diameter (0.8-1.2 $\mu \mathrm{m}$ pore size) is used as sampling medium [11].Total of 24 samples was collected in which two sample was rejected one because of damage on handling and another due to atmospheric disturbance (contaminations), so 22 sample were found suitable for fiber count valuation.

\subsection{Laboratory Analysis}

The sampled filter were carefully stored in separate sealed box by upright position and they labelled accordingly, in laboratory Acetone-Triacetin mounting procedure is followed for slide preparation and each slide were labelled. Phase contract light microscope (PCM) [14], [15] is the conventional equipment used to measure airborne particle here asbestos fibers are counted. Technically fiber with length greater than $5 \mu \mathrm{m}$ and width less than $3 \mu \mathrm{m}$ of aspect ratio greater than 3:1 were counted as single fiber. PCM AXIOSKOP 40 by magnification at $\mathrm{x} 400$ with WaltonBecket graticule G-22 was used for fiber counting. Minimum of one hundred graticule area were counted by following standard procedure. Fig. 2 was taken during fiber counting using PCM AXIOSKOP 40.

\subsection{Calculation}

Fiber concentration $\mathrm{C}(\mathrm{f} / \mathrm{cc})$ for each sample were calculated using formula
$\mathrm{C}=(\mathrm{A} / \mathrm{a}) *(\mathrm{~N} / \mathrm{n}) *(1 / \mathrm{r}) *(1 / \mathrm{t})$

To illustrate the estimation of fiber concentration one of sample from Moulded goods filling area is evaluated, with values from table 1 , here the total number of fiber counted 6.5 is applied that gives

$$
\begin{aligned}
\mathrm{C} & =(385.38 * 6.5) /(0.007857 * 100 * 1 * 1000 * 60) \\
& =0.053 \mathrm{f} / \mathrm{cc} .
\end{aligned}
$$

Table -1: Values Used In Formula

\begin{tabular}{|l|l|}
\hline \multicolumn{1}{|c|}{ Notation } & \multicolumn{1}{|c|}{ Value } \\
\hline A-effective filter area & $385.38 \mathrm{~mm} 2$ \\
a-graticule counting area & $0.007857 \mathrm{~mm} 2$ \\
N-total number of fiber counted & Vary \\
n-number of graticule area observed & 100 \\
r-flow rate of air through filter & 1 LPM \\
t-single sample duration & 60 minutes \\
\hline
\end{tabular}

\subsection{Picture}

Fig 1 and Fig 2 shows the pictures taken at study time while performing personal sampling and fiber counting respectively.

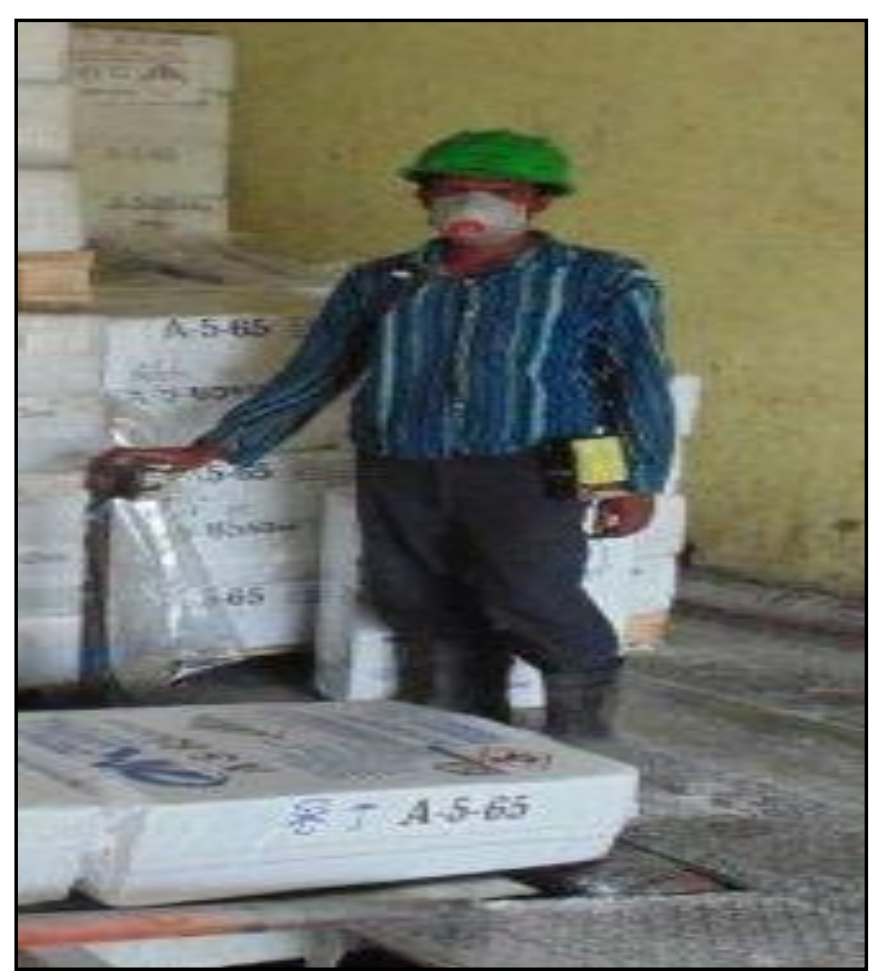

Fig -1: Edge runner mill area

Personal samples were collected during the workers performing their regular work, Fig -1 was taken at edge runner mill area while the worker supposed to loads asbestos bags in belt conveyor.

Fiber counting is most predominant work in fiber concentration estimation hence it is conducted in control environment which can be seen in fig -2 . 


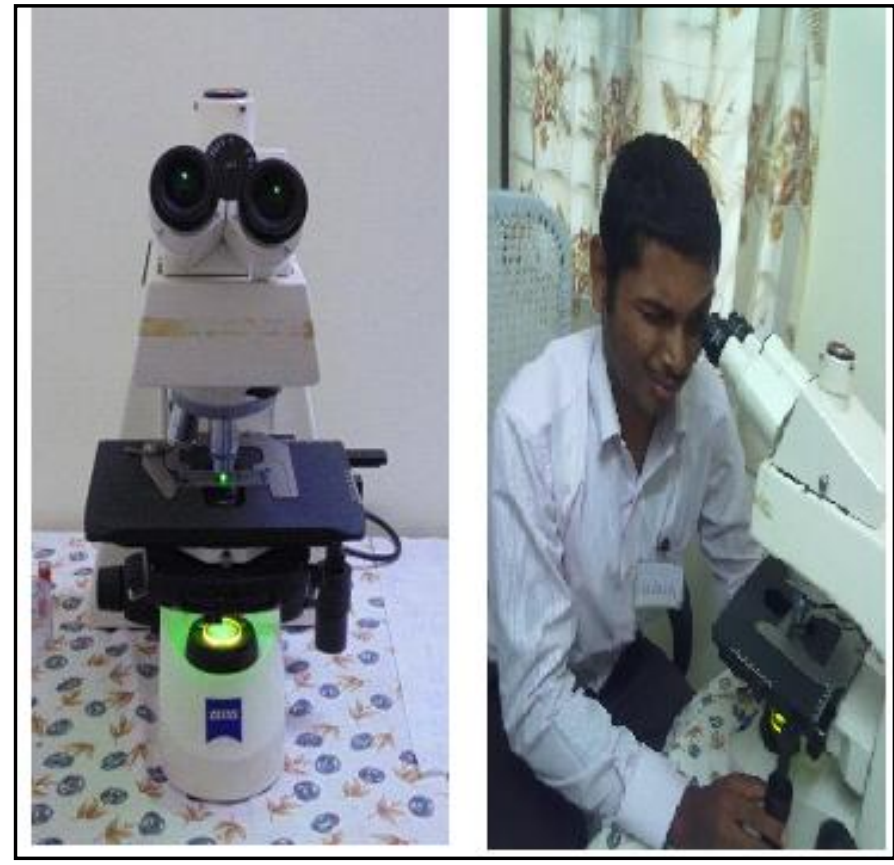

Fig -2: PCM

\section{RESULTS}

Table 2 shows the fiber concentration in geometric mean for individual personal sample, they were in the range of minimum $0.0195 \mathrm{f} / \mathrm{cc}$ and maximum $0.069 \mathrm{f} / \mathrm{cc}$ fiber sheet testing personal and wet ball mill respectively. Number of samples taken in each process/area are three but only one sample was taken at wet ball mill and main machine area. Sample at personal testing the sheet shows lowest concentration which holds various reason in that process. When compared to other personal samples wet ball mill area sample shows greater level of fiber concentration because in this area various activities like forklift movement, manual handling of sheet, rejects handling are carried out this may have influenced the concentration of fiber level.

Table 3 shows the results of individual static sample fiber concentration in geometric mean, in particular the static sampling at fiber stack is done at flow rate of 10 LPM for duration 10 minutes.

Table -2: Fiber Concentration Observed By Personal Sampling

\begin{tabular}{|c|l|c|}
\hline S No. & \multicolumn{1}{|c|}{ Process/Area (Samples) } & $\begin{array}{c}\text { Concentration, } \\
\text { f/cc }\end{array}$ \\
\hline 1 & Edge runner mill area (3) & 0.0395 \\
2 & Fiber sheet testing personal (3) & 0.0195 \\
3 & Moulded goods filling area (3) & 0.0581 \\
4 & Salvaging area (3) & 0.0315 \\
5 & Forklift driver on carrying fiber & 0.0207 \\
6 & bags (3) & 0.0690 \\
\hline
\end{tabular}

TABLE -3: Fiber Concentration Observed By Static Sampling

\begin{tabular}{|c|l|l|}
\hline S No. & Process/Area (Samples) & Concentration, f/cc \\
\hline 1 & Fiber storage area (3) & 0.0250 \\
2 & Fiber stack (3) & 0.0659 \\
3 & Main machine area (1) & 0.0280 \\
\hline
\end{tabular}

Due to high flow rate the fiber concentration was higher at stack but other static samples yield very negligible values. From table 2 and table 3 it reveals that results of no sample value exceeds the standard U.S. Environmental Protection Agency (0.1 fiber/cc), Occupational Safety and Health Administration (OSHA) Permissible Exposure Limit (0.1 fiber/cc), National Institute for Occupational Safety and Health (NIOSH) Recommended Exposure Limit (0.1 fiber/cc), American Conference of Governmental Industrial Hygienists (ACGIH) Threshold Limit Value (0.1 fiber/cc) [7], [15].

\section{DISCUSSION}

In this current study the overall airborne asbestos concentration tends to remain in lower level which shows the factory's safety performance to employee health. Safety precaution such as training program, protective clothing, statutory warning sign, smoking prohibition were observed during study period also no evidence of occupational ARD were found. Due to single sample representation, condition of area while sampling and by other discussed reasons wet ball mill area shows higher concentration, to obtain reliable result for this particular area more number of sampling is recommended. In future same study can be performed with advance technology involving high-resolution computed tomography (HRCT) [16], transmission electron microscope (TEM) [17].

Significant health risk can be found in smoker than nonsmokers because smoking act as catalyst for developing ARD so it is advised to cease smoking or never smoke [18], [19]. Nolan RP et al concluded that exposure to high level of asbestos might cause increase in kidney cancer [5].

India has banned the mining of asbestos fiber but not the manufacturing of asbestos containing materials (ACM), India import asbestos without warning sign but make export to Canada with warning sign indicating hazardous material [20], as most of developed countries has banned the manufacturing and use of asbestos and ACM, some developing countries like India had become the place of manipulating asbestos materials [14].

However the manufacture of $\mathrm{AC}$ is permitted the risk is unavoidable. If not, the safe control measure are followed throughout the life cycle of ACM starting from mining process to final disposal stage [21]. Our previous paper have immense detail about asbestos and its risk witnessed by various author from various period [22].

This study concludes that the level of fiber concentration observed from occupational exposure at cement sheet manufacturing was below the current standard limit, also worker are aware of asbestos. 


\section{ACKNOWLEDGEMENT}

Authors wish to thanks the affiliated institution and AC sheet manufacturing industry. M. Rajesh Kumar author morally thank internal and external supportive member for their guidance in various aspects.

\section{REFERENCES}

[1] Lee, H. J., Park, E. K., Wilson, D., Tutkun, E., \& Oak, C. (2013). Awareness of Asbestos and Action Plans for Its Exposure can Help Lives Exposed to Asbestos. Safety and health at work, 4(2), 84.

[2] Villeneuve, P. J., Parent, M. É., Harris, S. A., \& Johnson, K. C. (2012). Occupational exposure to asbestos and lung cancer in men: evidence from a population-based case-control study in eight Canadian provinces. BMC cancer, 12(1), 595.

[3] Bianchi, C., \& Bianchi, T. (2009). Malignant pleural mesothelioma in Italy. Indian journal of occupational and environmental medicine, 13(2), 80.

[4] Dopp, E., \& Schiffmann, D. (1998). Analysis of chromosomal alterations induced by asbestos and ceramic fibers. Toxicology letters, 96, 155-162.

[5] Sali, D., \& Boffetta, P. (2000). Kidney cancer and occupational exposure to asbestos: a meta-analysis of occupational cohort studies. Cancer Causes \& Control, 11(1), 37-47.

[6] Khan, A. H., Ansari, F. A., Misra, D., \& Bhargava, S. K. (2006). Study of asbestos fibre levels in and around a brake-lining industry. JOURNAL OF SCIENTIFIC AND INDUSTRIAL RESEARCH, 65(5), 437.

[7] Nolan, R. P., Langer, A. M., \& Wilson, R. (1999). A risk assessment for exposure to grunerite asbestos (amosite) in an iron ore mine. Proceedings of the National Academy of Sciences, 96(7), 3412-3419.

[8] Wollmer, P., Eriksson, L., Jonson, B., Jakobsson, K., Albin, M., Skerfving, S., \& Welinder, H. (1987). Relation between lung function, exercise capacity, and exposure to asbestos cement. British journal of industrial medicine, 44(8), 542-549.

[9] Lee, R. J., \& Van Orden, D. R. (2008). Airborne asbestos in buildings.Regulatory Toxicology and Pharmacology, 50(2), 218-225.

[10] Huncharek, M. (1987). Chrysotile asbestos exposure and mesothelioma. British journal of industrial medicine, 44(4), 287.

[11] Bureau of Indian Standards, IS-11450, 1986. Method for determination of air borne asbestos fibres concentration in work environment by light microscopy (Membrane filter method). Bureau of Indian Standard. New Delhi.

[12] Frost, G., Harding, A. H., Darnton, A., McElvenny, D., \& Morgan, D. (2008). Occupational exposure to asbestos and mortality among asbestos removal workers: a Poisson regression analysis. British journal of cancer, 99(5), 822-829.

[13] Baas, P., van't Hullenaar, N., Wagenaar, J., Kaajan, J. P. G., Koolen, M., Schrijver, M., ... \& Burgers, J. A. (2006). Occupational asbestos exposure: how to deal with suspected mesothelioma cases-the Dutch approach. Annals of oncology, 17(5), 848-852.

[14] Kakooei, H., \& Marioryad, H. (2010). Evaluation of exposure to the airborne asbestos in an automobile brake and clutch manufacturing industry in Iran.Regulatory Toxicology and Pharmacology, 56(2), 143-147.

[15] Jafari, M., Karimi, A., \& Bardshahi, A. M. (2010). Prediction of cancer mortality by evaluation of asbestos fibers concentrations in an asbestos-cement products factory. Iranian Journal of Environmental Health Science \& Engineering, 7(2).

[16] Vierikko, T., Järvenpää, R., Uitti, J., Virtema, P., Oksa, P., Jaakkola, M. S., ... \& Vehmas, T. (2008). The effects of secondhand smoke exposure on HRCT findings among asbestos-exposed workers. Respiratory medicine, 102(5), 658-664.

[17] Loomis, D., Dement, J., Richardson, D., \& Wolf, S. (2010). Asbestos fibre dimensions and lung cancer mortality among workers exposed to chrysotile.Occupational and environmental medicine, 67(9), 580-584.

[18] Jones, R. N., Hughes, J. M., \& Weill, H. (1996). Asbestos exposure, asbestosis, and asbestosattributable lung cancer. Thorax, 51(Suppl 2), S9-15.

[19] Erdinç, M., Erdinç, E., Çok, G., \& Polatli, M. (2003). Respiratory impairment due to asbestos exposure in brake-lining workers. Environmental research,91(3), 151-156.

[20] Ramanathan, A. L., \& Subramanian, V. (2001). Present Status of Asbestos Mining and Related Health Problems in India- A Survey. Industrial health, 39(4), 309-315.

[21] Phanprasit, W., Phanprasit, W., Sujirarat, D., Sujirarat, D., Chaikittiporn, C., \& Chaikittiporn, C. (2009). Health risk among asbestos cement sheet manufacturing workers in Thailand.

[22] M. Rajesh Kumar, R. Suresh, K. N. Karthick, \& H. Abdul Zubar, "A systematic literature review for statistical evaluation of asbestos exposure level," unpublished.

\section{BIOGRAPHIES}

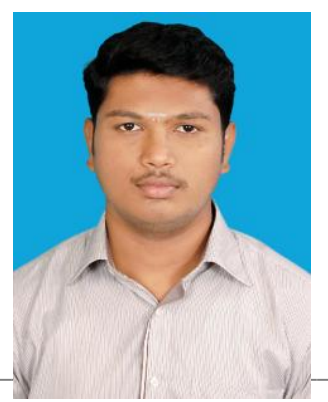

Mr. M. Rajesh Kumar was born in Namakkal city, Tamil nadu, India in 1991. He received the B.E. degree in Electronics and Communication Engineering from Paavai College of Engineering, Namakkal, Tamil Nadu, India, in 2012. He is currently 
pursuing the M.E. degree in Industrial Safety Engineering at Knowledge Institute of Technology, Salem, Tamil Nadu, India.

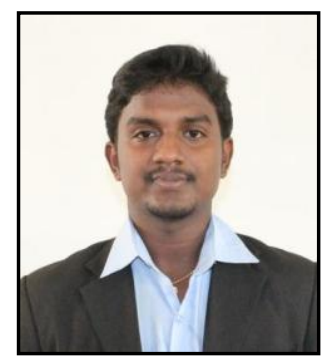

Mr. K. N. Karthick received the B.E. degree in mechanical engineering from K. S. Rangasamy College of Technology, Namakkal, Tamil Nadu, India, in 2010 and M.E. degree in Manufacturing Systems and Management from College of Engineering, Guindy, Anna University, Chennai, Tamil Nadu, India, in 2013. Since 2013, he has been an assistant professor with the Department of Mechanical Engineering at Knowledge Institute of Technology.

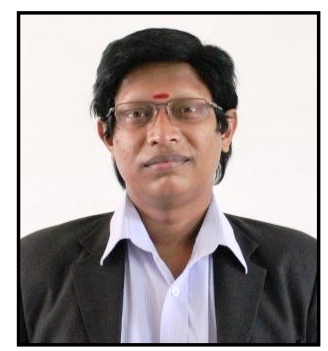

Mr. T.Dheenathayalan received the B.E. degree in Mechanical Engineering from Annamalai University, Chidambaram, Tamil Nadu, India, in 2007 and the M.E. degree in Industrial Safety Engineering from K. S. Rangasamy Institute of Technology, Namakkal, Tamil Nadu, India, in 2009. He received the MBA degree from Annamalai University Distance Education, Chidambaram, Tamil Nadu, India, in 2011. Since July 2010, he has been an assistant professor with the Department of Mechanical Engineering at Knowledge Institute of Technology.

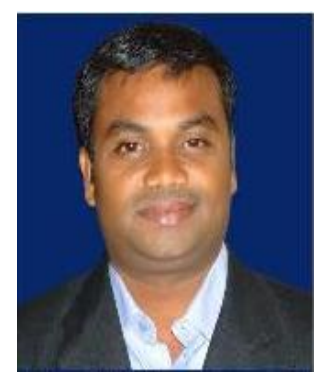

Dr. K. Visagavel received the B.E. and M.E. degree in Mechanical Engineering and Thermal Power Engineering from Annamalai University, Chidambaram, Tamil Nadu, India, in 1996 and 1998, respectively, and the $\mathrm{Ph} . \mathrm{D}$. degree in Heat Transfer and CFD from Anna University, Tamil Nadu, India, in 2009. From 1998 to 2009, he served as lecture, assistant professor, professor and Head in the Department of Mechatronics Engineering. Since April 2009, he has been a Professor, Head of the Mechanical Engineering department and Vice principal at Knowledge Institute of Technology. $\mathrm{He}$ is the author of three books, more than 41 articles. His research interests lie in thermal engineering. 